\title{
CRM1-dependent p53 nuclear accumulation in lung lesions of a bitransgenic mouse lung tumor model
}

\author{
LIXIA CHEN ${ }^{1}$, JOSEPH E. MOORE ${ }^{2}$, CHRISTINA SAMATHANAM $^{3}$, CHANGXIA SHAO $^{1}$, \\ EVERARDO COBOS ${ }^{4}$, MARK STEVEN MILLER ${ }^{2}$ and WEIMIN GAO ${ }^{1,4}$
}

\begin{abstract}
${ }^{1}$ Department of Environmental Toxicology, The Institute of Environmental and Human Health, Texas Tech University, Lubbock, TX 79409; ${ }^{2}$ Department of Cancer Biology, Comprehensive Cancer Center, Wake Forest University School of Medicine, Winston-Salem, NC 27157; Departments of ${ }^{3}$ Pathology and ${ }^{4}$ Internal Medicine, Texas Tech University Health Sciences Center, Lubbock, TX 79430, USA
\end{abstract}

Received November 17, 2010; Accepted January 7, 2011

DOI: 10.3892/or.2011.1279

\begin{abstract}
The p53 tumor suppressor gene plays an essential role in tumorigenesis, and the chromosomal region maintenance 1 (CRM1) has been suggested to export p53 protein from the nucleus to the cytoplasm. The objectives of the present study were to evaluate p53 expression and subcellular localization as well as CRM1 expression using immunohistochemistry in our established bitransgenic mouse lung tumor model. In this model, expression of the mutant human $\mathrm{Ki}-\mathrm{ras}^{\mathrm{G} 12 \mathrm{C}}$ allele was regulated in a doxycycline (DOX)-inducible, lung-specific manner. Following treatment with curcumin, we found that although overall p53 expression levels were not significantly changed among the three groups, lung lesions in mice treated with DOX alone had the highest proportion of $\mathrm{N}>\mathrm{C}$ (nucleus predominant) p53 staining $(46 \pm 7 \%)$, followed by lung lesions in mice co-treated with DOX and curcumin $(31 \pm 12 \%)$ and controls $(17 \pm 4 \%)$. CRM1 expression was dramatically inhibited in lung lesions in mice treated with DOX $(0 \pm 0)$ as compared to controls $(90 \pm 17$, $\mathrm{P}=0.001$ ), and could be partially reversed after curcumin treatment $(47 \pm 21, \mathrm{P}=0.028$, DOX vs. DOX+curcumin $)$. Collectively, the results from this study demonstrated that $\mathrm{p} 53$ accumulated in the nucleus in lung lesions in mice expressing the mutant $\mathrm{Ki}-\mathrm{ras}^{\mathrm{G}}{ }^{12 \mathrm{C}}$ transgene as a result of down-regulation of CRM1. Furthermore, these alterations could be partially
\end{abstract}

Correspondence to: Dr Weimin Gao, Department of Environmental Toxicology, The Institute of Environmental and Human Health (TIEHH), P.O. Box 41163, Texas Tech University, Lubbock, TX 79409, USA

E-mail: weimin.gao@tiehh.ttu.edu

Abbreviations: ABC, avidin-biotin complex; CRM1, chromosomal region maintenance 1 ; DAB, diaminobenzidine tetrahydrochloride; DOX, doxycycline; NNK, 4-(methylnitrosamino)-1-(3-pyridyl)-1butanone; PBS, phosphate-buffered saline

Key words: lung tumor, bitransgenic mouse, curcumin, chromosomal region maintenance $1, \mathrm{Ki}$-ras, p53 reversed by curcumin treatment. p53 subcellular localization resulting from CRM1 alterations may play an important role in lung tumorigenesis.

\section{Introduction}

Lung cancer is one of the most common cancers in the United States and worldwide (1). It still remains the leading cause of cancer death with an overall 5-year survival rate for all stages combined of only $15 \%$ (2). Ki-ras gene mutations play an important role in the pathogenesis of lung tumors as well as in prognosis $(3,4)$. To mimic the effects of oncogenic Ki-ras in human lung tumors with chemical carcinogen exposure, a bitransgenic mouse lung tumor model that expresses the mutant human Ki-ras ${ }^{\mathrm{G} 12 \mathrm{C}}$ allele in a doxycycline (DOX)inducible, lung-specific manner was previously generated (5). Benign lung lesions were observed with continuous $\mathrm{Ki}-\mathrm{ras}^{\mathrm{G} 12 \mathrm{C}}$ expression in bitransgenic mice after DOX exposure (5). Unexpectedly, curcumin, a chemopreventive agent, was found to cause an increase in lung tumor promotion of DOX-induced lung lesions in this model, possibly by enhancing reactive oxygen species formation (6).

It is well known that p53 is a critical tumor suppressor gene involved in the development of lung cancer (7). p53 inactivation through mutations occurs frequently in lung cancer $(40-70 \%)(8,9)$. Some tumors contain wild-type p53, which is functionally inactivated through other mechanisms, such as a change in subcellular localization $(10,11)$. Our previous in vitro cell culture study has shown that, in response to the mutagenic lung specific carcinogen 4-(methylnitrosamino)-1(3-pyridyl)-1-butanone (NNK), p53 is activated and retained in the nucleus, indicating that p53 exhibits a functional response to DNA damage (12). We also suggested that p53 nuclear accumulation might result from down-regulation of chromosomal region maintenance 1 (CRM1) (12). CRM1 is one of the important export factors that is involved in nucleo-cytoplasmic shuttling (13). CRM1 has been shown to export $\mathrm{p} 53$ from the nucleus to the cytoplasm, which might be an important regulatory pathway in carcinogenesis or drug resistance (14). 
In the present report, we extend our previous studies to evaluate the roles of CRM1 in regulating p53 subcellular localization in benign lung lesions from the bitransgenic mouse model and the modulating effects of curcumin in this process.

\section{Materials and methods}

Reagents. The following materials were purchased from the manufacturers listed. DOX, curcumin (95\% pure) and sodium citrate were purchased from Sigma. Primary rabbit polyclonal anti-CRM1 and anti-p53 were purchased from Santa Cruz Biotechnology. An avidin-biotin complex (ABC) kit and a diaminobenzidine tetrahydrochloride (DAB) kit were purchased from Vector Laboratories. Phosphate-buffered saline (PBS) was purchased from Bio-Rad Laboratories.

Bitransgenic mouse lung tumor model. Paraffin-embedded slides from transgenic mice were generated from our previous study on the effects of curcumin on lung tumor initiation and progression (6). The mice were either untreated, treated with DOX $(500 \mu \mathrm{g} / \mathrm{ml}$ in the drinking water) or co-treated with DOX and curcumin (1\% in the diet) for nine months. The mice were euthanized by $\mathrm{CO}_{2}$ asphyxiation/exsanguination and the lungs were then inflated and fixed in $10 \%$ phosphatebuffered formalin. Slides were prepared as described previously (6).

Immunostaining. Tissue slides were deparaffinized and antigen retrieval performed using $10 \mathrm{mM}$ sodium citrate buffer (pH 6.0) for $30 \mathrm{~min}$ at $95^{\circ} \mathrm{C}$. After cooling and subsequent rinsing in $1 \mathrm{X}$ PBS (pH 7.4), the slides were immersed in normal goat serum (1.5\%, Vector Laboratories) for $1 \mathrm{~h}$. The p53 (1:50 dilution) and CRM1 (1:50 dilution) primary antibodies were incubated overnight at $4^{\circ} \mathrm{C}$. Slides were then washed for $3 \times 3$ min with $1 \mathrm{X}$ PBS. Bound antibody was incubated with diluted biotinylated secondary antibody (1:2000, Vector Laboratories) for $1 \mathrm{~h}$. After washing with $1 \mathrm{X}$ PBS, sections were incubated for $30 \mathrm{~min}$ with VECTASTAIN ${ }^{\circledR}$ ABC Reagent (Vector Laboratories). DAB was used as the substrate to detect the antibody. Sections were then counterstained with hematoxylin.

Immunohistochemical analyses. To evaluate the protein expression of p53 and CRM1, stained sections of lung were semi-quantified using Image $\mathbf{J}$ software at $\mathrm{x} 40$ magnification to generate an 'H score' (15). In the modified $\mathrm{H}$ score, a score of ' 0 ' designates no stain, a score of ' 3 ' defines the darkest stain, with scores of ' 1 ' having weak staining and ' 2 ' having intermediate staining. For each section, 500 total cells from five randomly selected areas per section per animal were assessed for staining intensity and assigned a value from 0 to 3 for each image. The total $\mathrm{H}$ score for one section was subsequently generated by: $\mathrm{H}$ score $=\%$ cells with ' 0 ' score (negative) $+\%$ cells with ' 1 ' score (weakly positive) $+\%$ cells with ' 2 ' score (moderately positive) $+\%$ cells with ' 3 ' score (strongly positive), giving a possible range of 0-300. In addition, a quantitative measurement of the nuclear staining for p53 was also performed. Approximately 500 cells with staining from the same five randomly selected areas (100 cells per area), in which $\mathrm{H}$ score was evaluated, were further counted

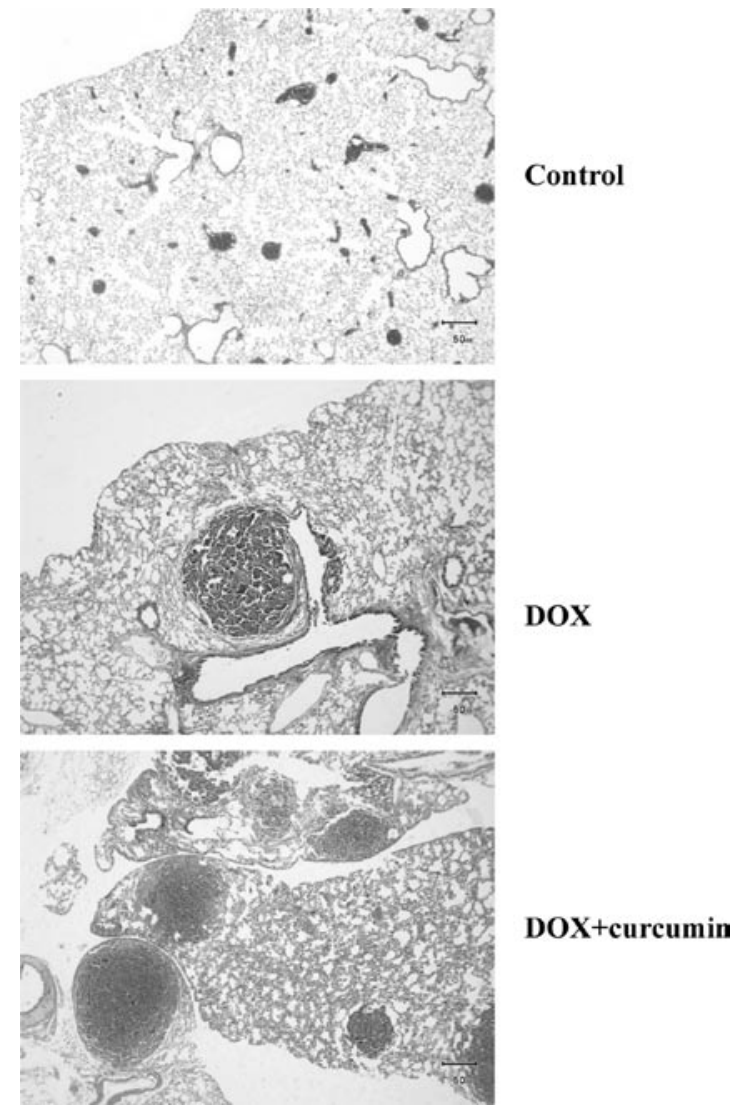

Figure 1. Photomicrographs of mouse lung tissue. Hematoxylin and eosin stains of tissue from control and treated mice, magnification $x 4$. (A) Normal lung tissue in control mouse. (B) Lung tissue in mouse treated with DOX. (C) Lung tissue in mouse treated with DOX and curcumin.

to calculate the proportion of each of the three patterns of p53 subcellular localization. The three different staining patterns for p53 subcellular localization included $\mathrm{N}>\mathrm{C}$ (majority of staining in the nucleus), $\mathrm{N}=\mathrm{C}$ (cells stained in the nucleus and cytoplasm equally) and $\mathrm{N}<\mathrm{C}$ (majority of staining in the cytoplasm). The differences of $\mathrm{p} 53$ subcellular localization among control, DOX and DOX+curcumin groups were compared. The slides were blindly examined by two pathologists.

Statistical analysis. Logistic regression was performed to test differences in the subcellular location of p53. One-way analysis of variance (ANOVA) was used to analyze $\mathrm{H}$ scores for p53 and CRM1 staining. Analyses were performed using the SPSS 13.0 software. Difference of $\mathrm{P}<0.05$ was considered significant.

\section{Results and Discussion}

p53 expression and nuclear accumulation in bitransgenic mouse lung tumor model. Slides from 5 mice from each group that had either been untreated, treated for 9 months with DOX alone to induce transgene expression or co-treated with DOX and $1 \%$ curcumin in the diet were used. As shown in Fig. 1, although curcumin treatment increased the number of lung neoplasms in the DOX+curcumin group, we observed no significant difference in tumor size, cytology or morphology of tumors between DOX treated and DOX+curcumin treated 
A

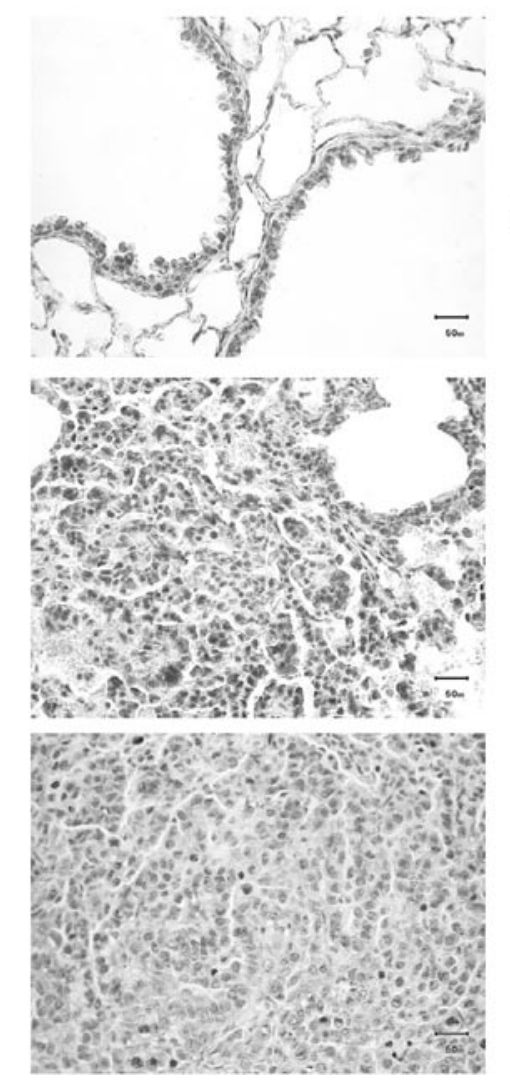

$\mathbf{B}$

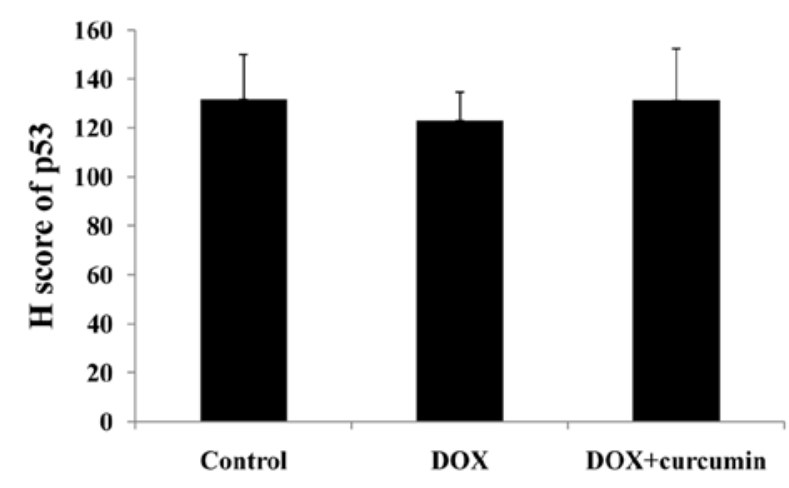

Treatment group

C

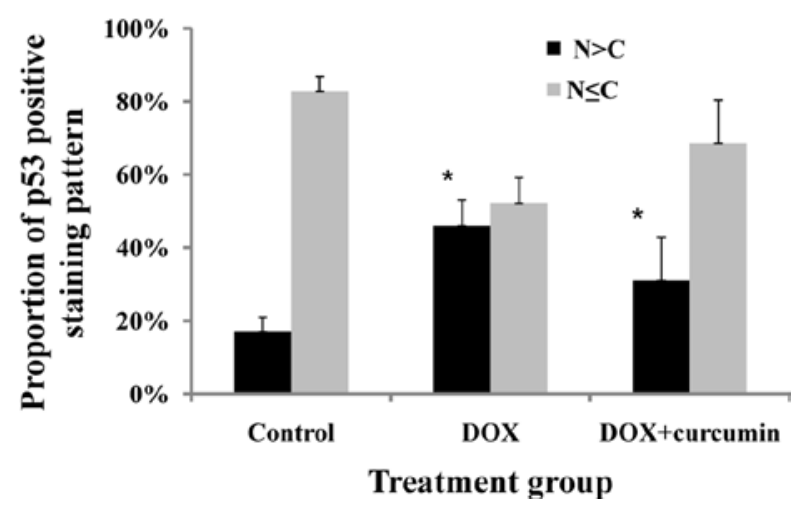

Figure 2. p53 expression and nuclear accumulations in a bitransgenic mouse lung tumor model. (A) Immunohistochemical analysis of p53 staining in lung tissues of a control mouse, lung lesions of a mouse treated with DOX, and lung lesions of a mouse treated with DOX and curcumin. Magnifications were $\mathrm{x} 40$ in each group. p53 demonstrated both nuclear and cytoplasmic staining. (B) Histogram displaying p53 expression in lung tissues of control mice, lung lesions in mice treated with DOX, and lung lesions in mice treated with DOX and curcumin. The intensity of p53 staining was evaluated by an H score of about 500 cells from five randomly selected areas per section per mouse in each group. Data were expressed as the mean \pm SE, $n=5$. (C) Histogram displaying the proportion of p53 staining in $\mathrm{N}>\mathrm{C}$ and $\mathrm{N} \leq \mathrm{C}$ pattern in lung tissues of control mice, lung lesions in mice treated with DOX, and lung lesions in mice treated with DOX and curcumin. About 100 cells with p53 staining per section were counted. Data were expressed as $\% \pm$ SE, $\mathrm{n}=5$. Asterisk indicates statistically significant $(\mathrm{P}<0.05)$.

groups in the subset of tumors utilized for this study. Paraffinembedded samples obtained from each mouse specimen were stained with p53 antibody. Both nuclear and cytoplasmic staining was observed (Fig. 2A). As shown in Fig. 2B, H scores of p53 in epithelial cells found no difference in the levels of total p53 protein expression in normal epithelial cells from the control group, lung lesions from mice treated with DOX, and lung lesions from mice co-treated with DOX and curcumin, which were $132 \pm 18,123 \pm 12$ and $131 \pm 21$, respectively $(\mathrm{P}=0.924)$. This result was in line with the data from our previous study showing the absence of p53 mutations in lung lesions from these mice (16).

As p53 is primarily a transcription factor, nuclear localization of activated p53 is essential for its transcriptional activity after stress exposure, such as DNA damage (17). We further evaluated p53 subcellular localization (Fig. 2C). The proportion of $\mathrm{N}>\mathrm{C}$ p53 staining in normal epithelial cells from the control group, lung lesions in mice treated with DOX, and lung lesions in mice co-treated with DOX and curcumin were $17 \pm 4 \%, 46 \pm 7 \%$ and $31 \pm 12 \%$, respectively. Lung lesions in mice treated with DOX or co-treated with DOX and curcumin had significantly higher proportions of $\mathrm{N}>\mathrm{C}$ p53 staining as compared to that of normal epithelial tissue in control mice $(\mathrm{P}<0.001$, DOX vs. control or DOX+curcumin vs. control). Furthermore, co-treatment with curcumin and DOX partially reversed the DOX effect on p53 nuclear accumulation $(\mathrm{P}<0.001$, DOX+curcumin vs. DOX). This result is in agreement with our previous finding, in which the activated form of $\mathrm{p} 53$, phosphorylated p53, was up-regulated in lung tumors in mice treated with DOX (16). It has also been suggested that when Ki-ras is activated by a genetic mutation, ataxia telangiectasia and $\operatorname{Rad} 3$ related (ATR) are activated and promote p53 expression (18). Collectively, these findings suggest that p53 is activated and accumulates in the nucleus in response to RAS mediated oncogenic signaling, which may partially account for the relatively benign phenotype of the lesions seen in this model following continuous DOX exposure. These phenomena have also been found in our in vitro study, in which activated p53 accumulated in the nucleus in response to DNA damage induced by NNK in the human lung epithelial cell line BEAS-2B (12).

CRM1 expression in bitransgenic mouse lung tumor model. p53 is actively transported between the nucleus and cytoplasm and is exported from the nucleus to the cytoplasm through 
A

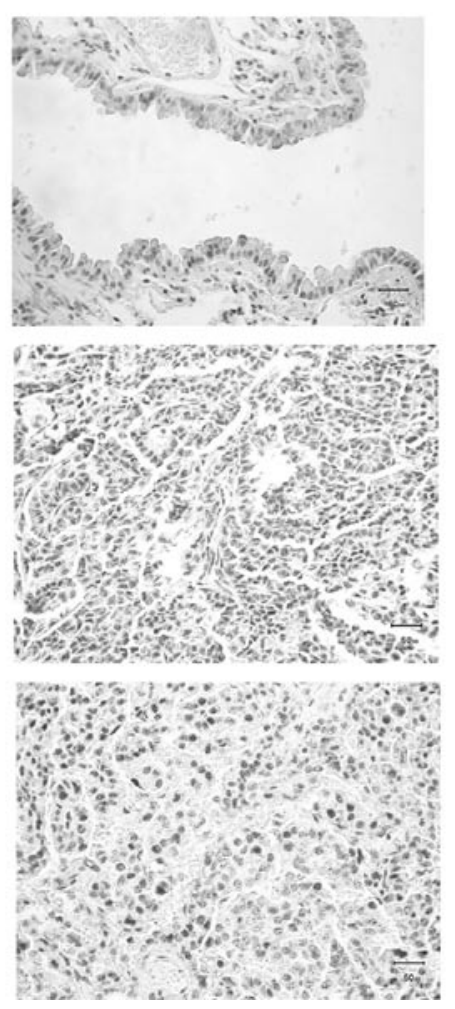

Control

DOX

\section{DOX + curcumin}

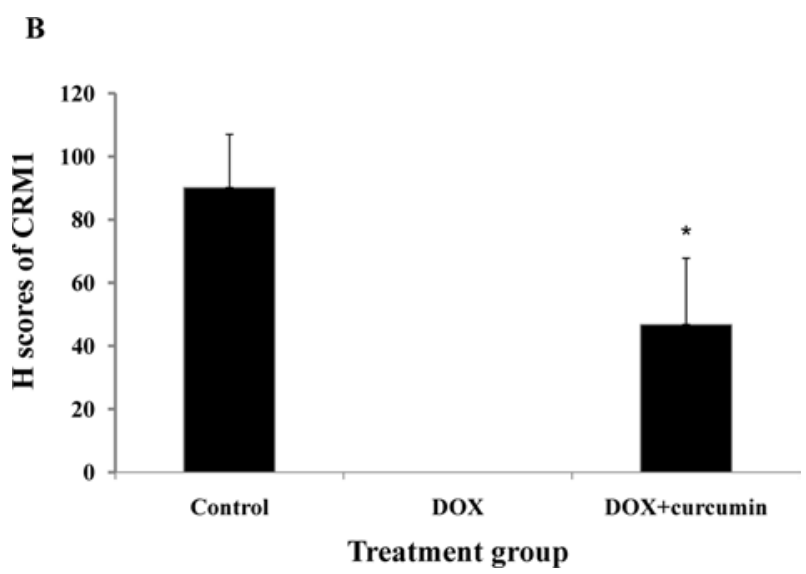

Figure 3. CRM1 expression in a bitransgenic mouse lung tumor model. (A) Immunohistochemical analysis of the lung with CRM1 antibody in lung tissues of a control mouse, lung lesions of a mouse treated with DOX, and lung lesions of a mouse treated with DOX and curcumin. Magnifications were $\mathrm{x} 40$ in each group. (B) Histogram displaying CRM1 expression in lung tissues of control mice, lung lesions in mice treated with DOX, and lung lesions in mice treated with DOX and curcumin. The intensity of CRM1 staining was evaluated by an $\mathrm{H}$ score of about 500 cells from five randomly selected areas per section per mouse in each group. Data were expressed as the mean $\pm \mathrm{SE}, \mathrm{n}=5$.

the CRM1 pathway (19). We further evaluated whether CRM1 expression in the lung lesions of DOX-treated bitransgenic mice was modulated by curcumin. The $\mathrm{H}$ scores of CRM1 in normal epithelial cells from the control group, lung lesions in mice treated with DOX, and lung lesions in mice co-treated with DOX and curcumin were $90 \pm 17,0 \pm 0$ and $47 \pm 21$, respectively (Fig. 3). CRM1 expression was dramatically inhibited in lung lesions in mice treated with DOX as compared to controls $(\mathrm{P}=0.001)$, and could be partially reversed by curcumin treat-

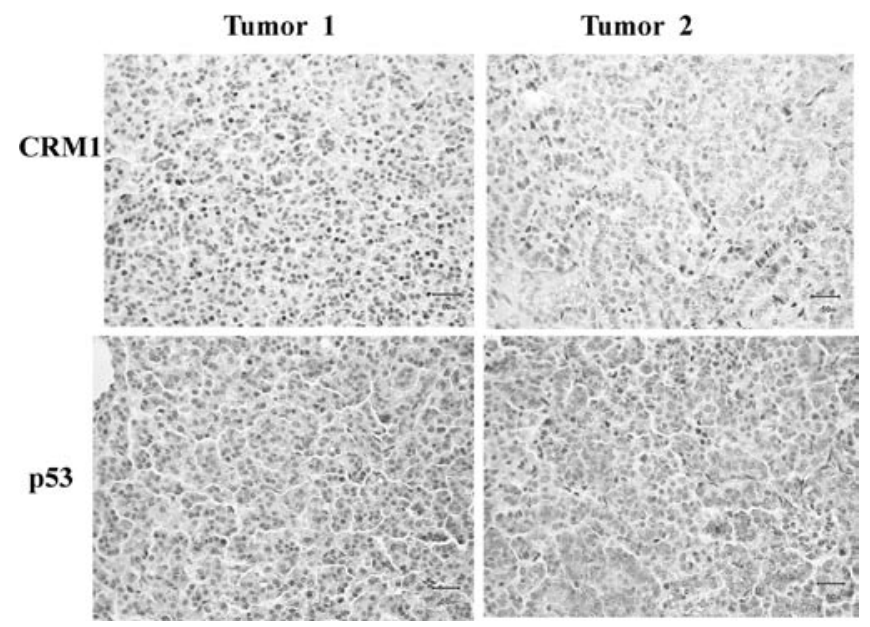

Figure 4. Different staining patterns of CRM1 and p53 in lung lesions treated with DOX and curcumin. Two representative areas were selected from two tumors in a mouse from DOX+curcumin group, $\mathrm{x} 40$ magnification. Tumor 1 has less CRM1 expression and a higher proportion of cells with p53 nuclear staining, while Tumor 2 has more CRM1 expression with a higher proportion of cells with p53 cytoplasmic staining.

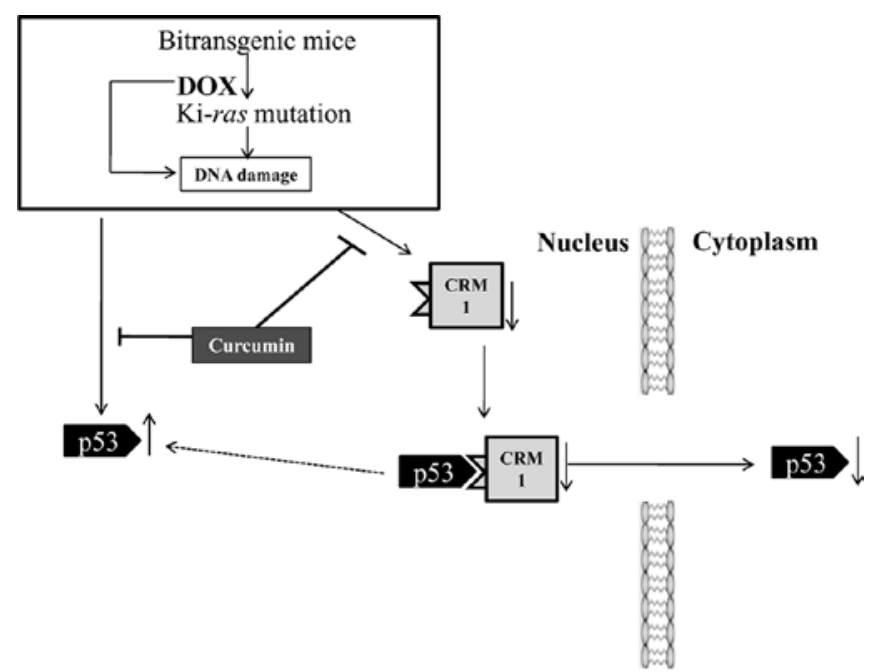

Figure 5. Flow chart of the proposed model in the bitransgenic Ki-ras ${ }^{\mathrm{G} 12 \mathrm{C}}$ mouse lung tumor. The experimental findings suggested that Ki-ras ${ }^{\mathrm{G} 12 \mathrm{C}}$ overexpression induced the accumulation of p53 in the nuclei of lung lesions from DOX-treated bitransgenic mice. In addition, CRM1 was down-regulated in bitransgenic mice treated with DOX as compared to control mice, which may contribute to p53 accumulation. Both p53 and CRM1 changes could be partially reversed by curcumin co-treatment of DOX induced mice.

ment $(\mathrm{P}=0.028$, DOX vs. DOX+curcumin). This suggests that down-regulation of CRM1 might contribute to p53 retention in the nucleus in response to mutant Ki-ras expression. In addition, different staining patterns of CRM1 and p53 in lung lesions within and between DOX and DOX+curcumin groups were observed, especially in mice treated with DOX+curcumin. As shown in Fig. 4, an inverse correlation in the staining patterns of CRM1 and p53 was observed; lung lesions with lower CRM1 expression tended to have a higher proportion of cells with p53 nuclear staining (Tumor 1 in Fig. 4), while lung lesions with higher CRM1 expression tended to have a 
lower proportion of cells with p53 nuclear staining. These data suggest that CRM1 can interact directly with p53 to modulate its subcellular localization in this mouse lung tumor model (Tumor 2 in Fig. 4). In line with this finding, studies from our groups and others suggested that CRM1 could directly bind to p53, providing further evidence of p53 localization through CRM1 pathways $(12,19)$. Taken together, the downregulation of CRM1 after $\mathrm{Ki}-\mathrm{ras}^{\mathrm{Gl}}{ }^{\mathrm{C}}$ expression could result in diminished p53 binding and p53 nuclear export, which could further lead to the nuclear accumulation of $\mathrm{p} 53$. The control of p53 localization between the nuclear and cytoplasmic compartments may be an important molecular mechanism for regulating p53 function in response to stress exposure. These findings also suggest that p53 and/or CRM1 alterations play important roles in lung tumorigenesis.

Curcumin, a major phenolic compound from the rhizome of the plant Curcuma longa, has anti-inflammatory, antioxidant and anti-cancer properties (20-22). A previous study conducted by Hecht et al with A/J mice co-treated with benzo[a]pyrene and NNK suggested that curcumin had no effect on lung tumor multiplicity in vivo, although its effects on tumor histology were not reported in this study (23). However, recent studies reported that pre-treatment with dietary curcumin prevented the initiation of lung tumors by benzo $[a]$ pyrene as a result of curcumin's effects on phase I and phase II enzyme levels in liver and lung tissues (24) and, in a different RAS-driven lung tumor transgenic mouse model, was found to inhibit Ki-ras induced lung cancer progression (25). In contrast, curcumin caused lung tumor promotion of DOX-induced lung lesions in this mouse model (6). These disparate findings in different mouse models suggest that the effects of curcumin on lung tumor initiation or progression may be modified by genetic factors. Whether these are due to differences intrinsic to the host or a result of differences in the effects of different RAS mutations remains to be determined. Several laboratories have demonstrated mutation-specific effects of different mutagenic RAS alleles on lung tumorigenesis in a variety of murine and cell culture models (26-34). On the other hand, the data of p53 and CRM1 alterations after curcumin treatment in the present study cannot exclude the possible protective effects of curcumin at the molecular levels against lung tumor progression.

CRM1 is the nuclear exporter for p53; therefore, downregulation of CRM1 might contribute to p53 retention in the nucleus in response to mutant $\mathrm{Ki}$-ras expression. In our recent in vitro study, CRM1 was down-regulated in response to NNK exposure (12). The direct evidence also showed that CRM1 could bind p53 and promote p53 shuttling between the nucleus and cytoplasm $(12,19)$. Mutational activation of Ki-ras appears to be an early event in tumorigenesis, especially in smokers (18). Our results suggest that mutant Ki-ras gene expression may lead to the down-regulation of CRM1 expression and the subsequent retention of p53 in the nucleus, thereby allowing the tumor suppressor to act as a defensive response to up-regulated RAS oncogenic signaling to prevent abnormal proliferation. Dance-Barnes et al recently reported that $\mathrm{Ki}$-ras and curcumin mediated changes in oxidative stress and inflammation in the tumor microenvironment of this mouse model (6). On the other hand, data by others have indicated that the levels of CRM1 are sensitive to changes in oxidative stress and inflammation response (35-38). For example, oxidative stress could inhibit nuclear protein export by multiple mechanisms that target CRM1 (36), and proteins involved in inflammation processes could be mediated by CRM1 $(35,37,38)$. Therefore, it is also possible that RAS or curcumin or both compounds may influence CRM1 expression via other signaling pathways.

In summary, we demonstrated that increased expression of the mutant RAS transgene in mouse lungs resulted in the accumulation of p53 in the nuclei of lung lesions. The expression of CRM1 was down-regulated in these same lesions. The data thus suggest that the oncogene-mediated decrease in CRM1 expression attenuates the export of activated p53 from the nucleus to the cytoplasm, allowing the cell to mount a defensive response as a result of the inappropriate oncogene signaling. Furthermore, we found that curcumin could reduce the responses of p53 nuclear accumulation and CRM1 downregulation in lung lesions after DOX treatment (Fig. 5).

\section{References}

1. Jemal A, Murray T, Ward E, et al: Cancer statistics, 2005. CA Cancer J Clin 55: 10-30, 2005.

2. Cancer Facts and Figures 2010. American Cancer Society, Atlanta, GA, 2010

3. Schneider PM, Praeuer HW, Stoeltzing O, et al: Multiple molecular marker testing (p53, C-Ki-ras, c-erbB-2) improves estimation of prognosis in potentially curative resected non-small cell lung cancer. Br J Cancer 83: 473-479, 2000.

4. Sugio K, Ishida T, Yokoyama H, Inoue T, Sugimachi $K$ and Sasazuki T: Ras gene mutations as a prognostic marker in adenocarcinoma of the human lung without lymph node metastasis. Cancer Res 52: 2903-2906, 1992.

5. Floyd HS, Farnsworth CL, Kock ND, et al: Conditional expression of the mutant Ki-ras(G12C) allele results in formation of benign lung adenomas: development of a novel mouse lung tumor model. Carcinogenesis 26: 2196-2206, 2005.

6. Dance-Barnes ST, Kock ND, Moore JE, et al: Lung tumor promotion by curcumin. Carcinogenesis 30: 1016-1023, 2009.

7. Sengupta $S$ and Harris CC: p53: traffic cop at the crossroads of DNA repair and recombination. Nat Rev Mol Cell Biol 6: 44-55, 2005.

8. Toyooka S, Tsuda T and Gazdar AF: The TP53 gene, tobacco exposure, and lung cancer. Hum Mutat 21: 229-239, 2003.

9. Mao L: Molecular abnormalities in lung carcinogenesis and their potential clinical implications. Lung Cancer 34: S27-S34, 2001.

10. Ryan KM, Phillips AC and Vousden KH: Regulation and function of the p53 tumor suppressor protein. Curr Opin Cell Biol 13: 332-337, 2001.

11. Uldrijan S, Kotala V and Vojtesek B: Regulation of the p53 tumour suppressor stability and activity. Chemicke Listy 96: 145-149, 2002.

12. Chen L, Shao C, Cobos E, Wang JS and Gao W: 4-(methylnitrosamino)-1-(3-pyridyl)-1-butanone [corrected] induces CRM1-dependent p53 nuclear accumulation in human bronchial epithelial cells. Toxicol Sci 116: 206-215, 2010.

13. Kudo N, Khochbin S, Nishi K, et al: Molecular cloning and cell cycle-dependent expression of mammalian CRM1, a protein involved in nuclear export of proteins. J Biol Chem 272: 29742-29751, 1997.

14. Wang SC and Hung MC: Cytoplasmic/nuclear shuttling and tumor progression. Ann N Y Acad Sci 1059: 11-15, 2005.

15. Umemura S, Itoh J, Itoh $\mathrm{H}$, et al: Immunohistochemical evaluation of hormone receptors in breast cancer - which scoring system is suitable for highly sensitive procedures? Applied Immunohistochem Mol Morphol 12: 8-13, 2004.

16. Floyd HS, Jennings-Gee JE, Kock ND and Miller MS: Genetic and epigenetic alterations in lung tumors from bitransgenic Ki-ras(G12C) expressing mice. Mol Carcinog 45: 506-517, 2006.

17. Meek DW: Tumour suppression by p53: a role for the DNA damage response? Nat Rev Cancer 9: 714-723, 2009.

18. Lee SH, Lee SJ, Jung YS, et al: Blocking of p53-Snail binding, promoted by oncogenic K-Ras, recovers p53 expression and function. Neoplasia 11: 22-31, 2009. 
19. Kanai M, Hanashiro K, Kim SH, et al: Inhibition of Crm1-p53 interaction and nuclear export of p53 by poly(ADP-ribosyl)ation. Nat Cell Biol 9: 1175-1183, 2007.

20. Anand P, Thomas SG, Kunnumakkara AB, et al: Biological activities of curcumin and its analogues (Congeners) made by man and Mother Nature. Biochem Pharmacol 76: 1590-1611, 2008.

21. Chen L, Tian G, Shao C, Cobos E and Gao W: Curcumin modulates eukaryotic initiation factors in human lung adenocarcinoma epithelial cells. Mol Biol Rep 37: 3105-3110, 2010.

22. Shishodia S, Chaturvedi MM and Aggarwal BB: Role of curcumin in cancer therapy. Curr Probl Cancer 31: 243-305, 2007.

23. Hecht SS, Kenney PMJ, Wang MY, et al: Evaluation of butylated hydroxyanisole, myo-inositol, curcumin, esculetin, resveratrol and lycopene as inhibitors of benzo[a]pyrene plus 4-(methylnitrosamino)-1-(3-pyridyl)-1-butanone-induced lung tumorigenesis in A/J mice. Cancer Lett 137: 123-130, 1999.

24. Garg R, Gupta S and Maru GB: Dietary curcumin modulates transcriptional regulators of phase I and phase II enzymes in benzo[a]pyrene-treated mice: mechanism of its anti-initiating action. Carcinogenesis 29: 1022-1032, 2008.

25. Moghaddam SJ, Barta P, Mirabolfathinejad SG, et al: Curcumin inhibits COPD-like airway inflammation and lung cancer progression in mice. Carcinogenesis 30: 1949-1956, 2009.

26. Cespedes MV, Sancho FJ, Guerrero S, et al: K-ras Asp12 mutant neither interacts with Raf, nor signals through Erk and is less tumorigenic than K-ras Val12. Carcinogenesis 27: 2190-2200, 2006.

27. Finkelstein SD, Sayegh R, Bakker A, et al: Determination of tumor aggressiveness in colorectal-cancer by K-ras-2 analysis. Arch Surg 128: 526-532, 1993.

28. Finkelstein SD, Sayegh R, Christensen S and Swalsky PA: Genotypic classification of colorectal adenocarcinoma-bilogic behavior correlates with K-ras-2 mutation type. Cancer 71: $3827-3838,1993$.

29. Gressani KM, Leone-Kabler S, O'Sullivan MG, Case LD, Malkinson AM and Miller MS: Strain-dependent lung tumor formation in mice transplacentally exposed to 3-methylcholanthrene and post-natally exposed to butylated hydroxytoluene. Carcinogenesis 20: 2159-2165, 1999.
30. Jennings-Gee JE, Moore JE, Xu M, et al: Strain-specific induction of murine lung tumors following in utero exposure to 3-methylcholanthrene. Mol Carcinog 45: 676-684, 2006.

31. Keohavong P, DeMichele MAA, Melacrinos AC, Landreneau RJ, Weyant RJ and Siegfried JM: Detection of K-ras mutations in lung carcinomas: relationship to prognosis. Clin Cancer Res 2: 411-418, 1996.

32. LeoneKabler S, Wessner LL, McEntee MF, Dagostino RB and Miller MS: Ki-ras mutations are an early event and correlate with tumor stage in transplacentally-induced murine lung tumors. Carcinogenesis 18: 1163-1168, 1997.

33. Li EE, Heflich RH, Bucci TJ, Manjanatha MG, Blaydes BS and Delclos KB: Relationships of DNA adduct formation, K-ras activating mutations and tumorigenic activities of 6-nitrochrysene and its metabolites in the lungs of CD-1 mice. Carcinogenesis 15: 1377-1385, 1994.

34. Nuzum EO, Malkinson AM and Beer DG: Specific Ki-ras codon 61 mutations may determine the development of urethaneinduced mouse lung adenomas or adenocarcinomas. Mol Carcinog 3: 287-295, 1990.

35. Beck IM, van den Berghe W, Vermeulen L, et al: Altered subcellular distribution of MSK1 induced by glucocorticoids contributes to NF-kappaB inhibition. EMBO J 27: 1682-1693, 2008.

36. Crampton N, Kodiha M, Shrivastava S, Umar R and Stochaj U: Oxidative stress inhibits nuclear protein export by multiple mechanisms that target FG nucleoporins and Crm1. Mol Biol Cell 20: 5106-5116, 2009

37. Muller PA, van de Sluis B, Groot AJ, et al: Nuclear-cytosolic transport of COMMD1 regulates NF-kappaB and HIF-1 activity. Traffic 10: 514-527, 2009.

38. Tang D, Kang R, Xiao W, Wang H, Calderwood SK and Xiao X: The anti-inflammatory effects of heat shock protein 72 involve inhibition of high-mobility-group box 1 release and proinflammatory function in macrophages. J Immunol 179: 1236-1244, 2007. 